\title{
An analytical solution for temperature distribution in fillet arc welding based on an adaptive function
}

\author{
Mohammad Bagher Nasiri $^{1}$ (i) $\cdot$ Norbert Enzinger $^{1}$
}

Received: 19 April 2018 / Accepted: 18 October 2018 /Published online: 31 October 2018

(C) The Author(s) 2018

\begin{abstract}
This paper presents an analytical solution that can be applied to predict temperature distribution in fillet welds using adaptive function approach developed by authors. The adaptive function method is a general approach to solve the partial differential equation of engineering problem based on developing a flexible function of dimensionless parameters, which circumvent the simplification assumptions required in numerical and analytical solutions proposed so far. This paper intends to develop the adaptive function by manipulating Rosenthal's equation so that it can be adjusted according to the experimental data, which are the weld pool dimensions and temperature measured at some arbitrary points. To apply the adaptive function in a fillet weld, a new coordinate system is defined in which the $x$-axis is parallel to the legs of the fillet weld (width direction of the weld plate), the $y$-axis is parallel to the welding trajectory, and the $z$-axis is parallel to the penetration of the weld (depth direction of the weld plate). A polar coordinate system is defined for the corner part of the fillet weld. The adaptive function in this part is defined to preserve the consistency of the isotherms. The experimental data were provided by performing GTAW on a stainless steel 316L with various welding current. The results indicate that the novel approach is fast and simple and agrees well with results from experiments.
\end{abstract}

Keywords Welding simulation $\cdot$ Heat flow $\cdot$ Analytical solution $\cdot$ Fillet weld

\section{Nomenclature \\ $\mathrm{a}_{\mathrm{m}} \quad$ Adaptive function parameter for $\mathrm{x}$ direction \\ $\mathrm{b}_{\mathrm{m}} \quad$ Adaptive function parameter for $\mathrm{y}$ direction \\ B Adaptive function parameter \\ $\mathrm{c}_{\mathrm{m}} \quad$ Adaptive function parameter for $\mathrm{z}$ direction \\ c Specific heat \\ d Adaptive function parameter \\ D Depth of the weld pool \\ $\mathrm{k} \quad$ Heat conductivity \\ $\mathrm{L}_{\mathrm{r}} \quad$ Length of the rear tail of the weld pool \\ $\mathrm{L}_{\mathrm{f}} \quad$ Length of the front part of the weld pool}

Recommended for publication by Commission IX - Behaviour of Metals Subjected to Welding

Mohammad Bagher Nasiri

mohammad.nasiri@tugraz.at

Norbert Enzinger

Norbert.enzinger@tugraz.at

1 Institute of Materials Science, Joining and Forming, Graz University of Technology, 8010 Graz, Austria

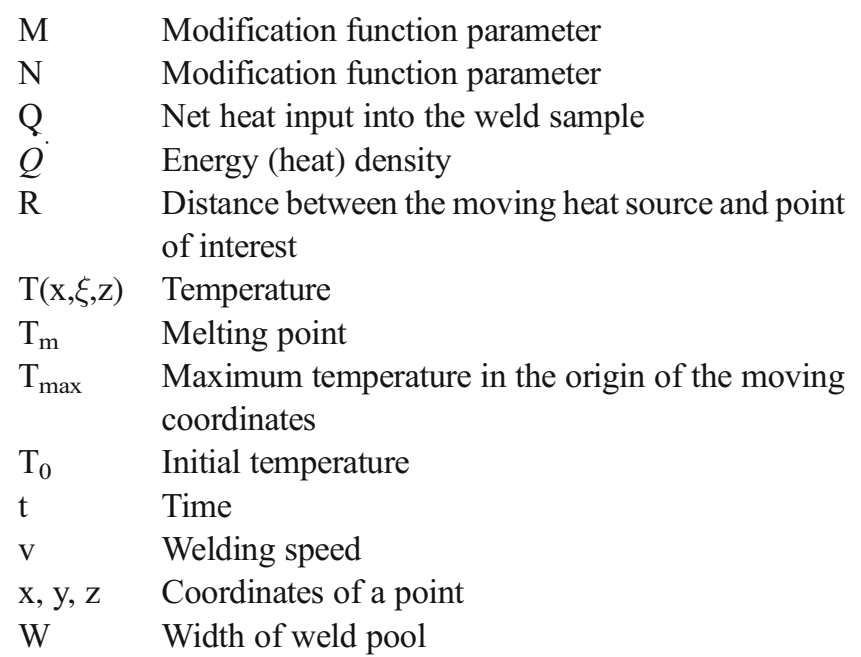

\section{Greek symbols}

$\alpha$ Thermal diffusivity

$\xi \quad$ Moving coordinate parallel to the welding trajectory

$\rho$ Density

$\omega$ Dimensionless parameter

$\delta \quad$ Adaptive function parameter 


\section{Introduction}

The methods that have been proposed to solve the heat flow problem in welding can be assigned to one of three major groups: analytical, modified analytical, and numerical approaches $[1,2]$.

From a practical perspective, the analytical solution has the advantage of being extremely fast [3]. However, the application of this solution is restricted because of its limited accuracy in the case of engineering problems [4]. As a consequence, several authors have attempted to modify the analytical solution to achieve higher accuracy, but these attempts have shown only limited success [5-8]. On the other hand, numerical solutions are relatively accurate, but require highcomputational costs [9].

From the physical perspective, the main obstacles to finding an appropriate solution to the heat flow problem in welding can be summarized as follows:

- The first problem is the existence of four physically different zones that are involved in the welding process including the surrounding air, plasma, molten pool, and solid region in which different heat transfer modes are dominant. To overcome these problems, all zones except the solid region are usually ignored and substituted by a boundary condition.

- The second problem concerns the boundary conditions, which are difficult to determine correctly. The heat source model and heat flux in the boundary of the model, in particular, are both equally important and challenging issues [10]. Calibrating the heat source model, which is always done by trial and error, results in higher costs for a welding simulation [11].

- The third obstacle is the temperature-dependent thermophysical properties, which result in the nonlinearity of the partial differential equation. The nonlinear partial differential equations can rarely be solved by analytical methods, and numerical solution of them is achieved by iterative methods which increase the calculation time [10].

Most of the analytical and modified analytical solutions have been developed for a bead on plate welding $[3,7,8]$, while fillet arc welding is more commonly used in industries [12]. Jeong and Cho developed an analytical solution for the transient temperature distribution in fillet arc welding by

Table 1 Parameters of the welding process

\begin{tabular}{lllllll}
\hline $\begin{array}{l}\text { Voltage } \\
(\mathrm{V})\end{array}$ & $\begin{array}{l}\text { Welding } \\
\text { current } \\
(\mathrm{A})\end{array}$ & $\begin{array}{l}\text { Speed } \\
(\mathrm{mm} / \mathrm{s})\end{array}$ & $\begin{array}{l}\text { Shielding } \\
\text { gas }\end{array}$ & $\begin{array}{l}\text { Flow } \\
\text { rate } \\
(\mathrm{cfh})\end{array}$ & $\begin{array}{l}\text { Electrode } \\
\text { diameter } \\
(\mathrm{mm})\end{array}$ & $\begin{array}{l}\text { Arc } \\
\text { length } \\
(\mathrm{mm})\end{array}$ \\
\hline 14.6 & 150 & 1.5 & Argon & 40 & 2.4 & 3 \\
\hline
\end{tabular}

Table 2 Dimensions of the welding plate

Plate size (mm)

\begin{tabular}{lll}
\hline Width & Length & Thickness \\
100 & 200 & 10 \\
\hline
\end{tabular}

considering a bivariate Gaussian distribution [12]. The inherent characteristics of the numerical solution allow researchers to consider complex welding geometry, while the analytical solution still encounters with the problem of complex geometries.

A new approach is presented here to solve the partial differential equation (PDE) based on an adaptive function in order to overcome the obstacles described. In this paper, a simple technique is presented which can be applied in a large number of cases to circumvent the difficulties of the heat flow solution in welding.

\section{Experimental setup}

In order to show the evolution of the adaptive function, a Gas Tungsten Arc Welding (GTAW) process with welding parameters given in Table 1 was applied on a 316 L stainless plate with the dimensions given in Table 2, and the chemical composition given in Table 3. Experimental data including weld pool dimension and temperatures measured at some arbitrary points were extracted to be used in modeling and validation of the models. The temperature history of points at positions shown in Fig. 1 were measured by type $\mathrm{K}$ thermocouples (0.3 $\mathrm{mm}$ in diameter). After welding, the width (W), depth (D), rear tail $\left(\mathrm{L}_{\mathrm{r}}\right)$, and front radius $\left(\mathrm{L}_{\mathrm{f}}\right)$ of the weld pool were measured on the sample and are presented in Table 4.

\section{Solution procedure}

\subsection{General (Rosenthal) solution}

According to the law of energy conservation, the partial differential equation of heat flow due to a moving heat source can be described as follows:

$\rho c\left(\frac{\partial T}{\partial t}+v \nabla T\right)=\nabla \cdot(\mathrm{k} \nabla \mathrm{T})+\dot{Q}$

Table 3 Chemical composition of the stainless steel 316L plate

\begin{tabular}{llllllllll}
\hline Element & $\mathrm{C}$ & $\mathrm{Mn}$ & $\mathrm{P}$ & $\mathrm{S}$ & $\mathrm{Si}$ & $\mathrm{Cr}$ & $\mathrm{Ni}$ & $\mathrm{Mo}$ & $\mathrm{N}$ \\
\hline Weight \% & 0.03 & 2 & 0.045 & 0.03 & 0.75 & 18 & 14 & 3 & 0.1 \\
\hline
\end{tabular}


Fig. 1 Schematic of a quarter of the welding plate and the position of the thermocouples

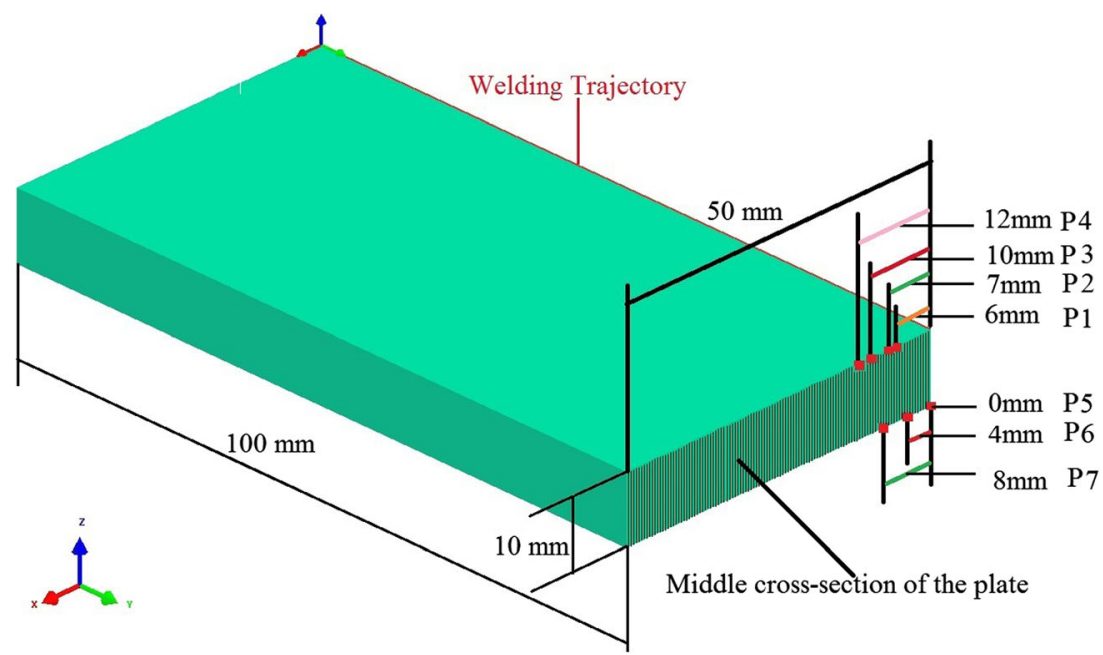

$R=\sqrt{x^{2}+\xi^{2}+z^{2}}$

If the heat source travels along the $y$-axis, and the physical properties and the temperature distribution around the heat source are assumed to be constant, Eq. 1 can be rewritten in a quasi-steady state [3]:

$\xi=y-v t$

$\frac{\rho c v}{\mathrm{k}} \frac{\partial \mathrm{T}}{\partial \xi}=\nabla^{2} T+\frac{\dot{Q}}{k}$

According to the Rosenthal assumptions [3] and the solution to the Helmholtz equation, the general solution will be:

$T=T_{0}+\frac{Q}{2 \pi k R} e^{\left(-\frac{\rho c}{2 k}(R+\xi)\right)}$

Table 4 Weld pool dimensions (mm)

\begin{tabular}{llll}
\hline $\mathrm{W}$ & $\mathrm{L}_{\mathrm{f}}$ & $\mathrm{L}_{\mathrm{r}}$ & $\mathrm{D}$ \\
\hline 4.5 & 3.5 & 7 & 1.9
\end{tabular}

The principle of the new method is based on developing a function so that it can be matched to the measured temperature by determining some limited parameters and this is termed the adaptive function.

\subsection{Result of the Rosenthal's solution}

Figure 2 shows the temperature distribution on the upper surface of the plate as calculated with the Rosenthal equation (Eq. 4). The constant thermo-physical properties of AISI 316L stainless steel at room temperature were used for the temperature calculation (Table 5), and the arc thermal efficiency of GTAW was considered to be 0.7 [13].

As shown in Fig. 2, the temperature at the origin of the moving coordinate is infinite due to the assumed point heat source. Since the Rosenthal solution considers a conduction
Fig. 2 Temperature distribution on the upper surface of the $316 \mathrm{~L}$ plate as calculated with the Rosenthal equation

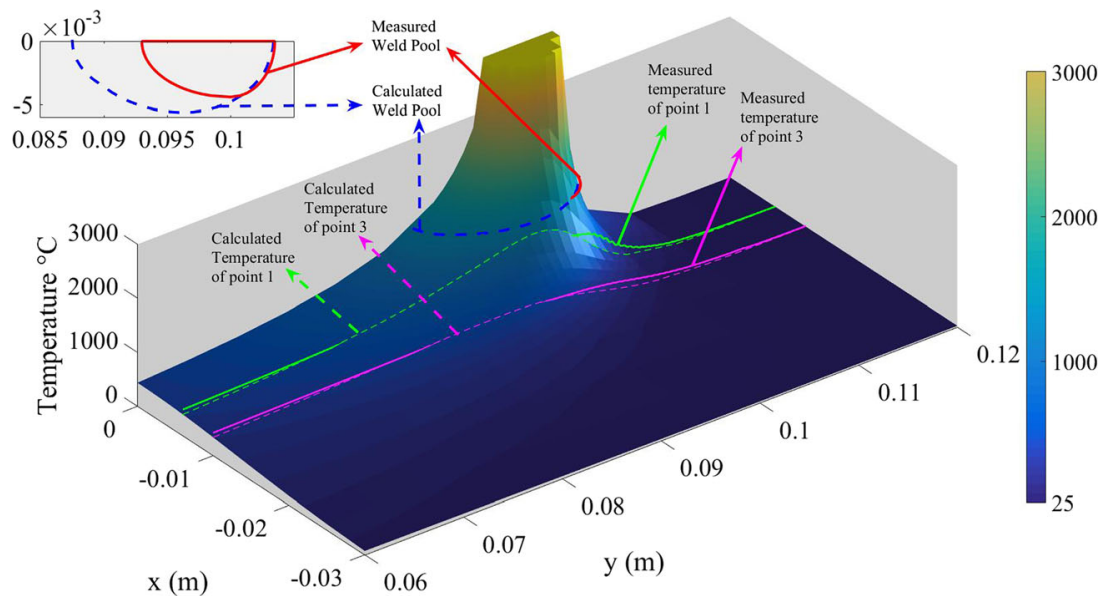


Table 5 Material properties of AISI 316L at room temperature used for the Rosenthal equation [14-16]

\begin{tabular}{llll}
\hline $\begin{array}{l}\text { Heat } \\
\text { capacity } \\
\left(\mathrm{J} / \mathrm{kg}{ }^{\circ} \mathrm{C}\right)\end{array}$ & $\begin{array}{l}\text { Density } \\
\left(\mathrm{kg} / \mathrm{m}^{2}\right)\end{array}$ & $\begin{array}{l}\text { Conductivity } \\
(\mathrm{J} / \mathrm{m})\end{array}$ & $\begin{array}{l}\text { Melting } \\
\text { point } \\
\left({ }^{\circ} \mathrm{C}\right)\end{array}$ \\
\hline 495 & 7990 & 15 & 1400 \\
\hline
\end{tabular}

heat transfer mode with constant physical properties of the material, while the fluid flow convection is the dominant heat transfer mode in the weld pool, the predicted weld pool dimensions are different compared to the measurement as shown in Fig. 2.

By considering the quasi-steady state condition, the measured temperature history of a point can be converted into a spatial temperature distribution along the $y$-axis using Eq. 2 . Accordingly, the temperature distribution along the $y$-axis, 6 and $10 \mathrm{~mm}$ away from the centerline, were calculated according to the recorded temperatures at points P1 and P3 (Fig. 2).

Figure 3 shows that the heating and cooling rates predicted by Eq. 4 are significantly different from the measurement, which is partly due to the simplified boundary conditions and partly due to assumed constant physical properties of the material.

\subsection{Configuration of the adaptive function}

Regardless of the restrictive assumptions that have been made by Rosenthal, the rigid formulation of Eq. 4 does not allow for changes in such a way that the result can be matched to the measured temperature. For instance, it is not possible to match the calculated melting point isotherm with the observed fusion line by changing the parameters of Eq. 4 .

However, this paper intends to show the development of an adaptive function describing the temperature distribution by manipulating the Rosenthal equation so that the calculated fusion line coincides with the measurement.

\subsubsection{Matching the weld pool}

The term $R$ (Eq. 5) in the Rosenthal solution is the mathematical equation of a sphere, which is a special form of an ellipsoid. By replacing $R$ with $R_{p}^{*}$ (Eq. 6), which is the equation of an ellipsoid, the calculated melting isotherm can be matched with the measured fusion line by finding the parameters of the Eq. 6 including $a, b, c$, and $\mathrm{d}$.

$R_{p}^{*}=\sqrt{\left(\frac{x}{a}\right)^{2}+\left(\frac{\xi}{b}\right)^{2}+\left(\frac{z}{c}\right)^{2}+d^{2}}$

$T=T_{0}+\frac{Q}{2 \pi k R_{p}^{*}} e^{\left(-\frac{\rho c \nu}{2 k}(R+\xi)\right)}$

Equation 7 can be simplified by bringing the term $\frac{Q}{2 \pi k}$ under the square of $R_{p}^{*}$, thus simplifying the mathematical expression of $T$.

$R_{p}=\frac{Q}{2 \pi k} \times R_{p}^{*}=\frac{Q}{2 \pi k}$

$$
\times \sqrt{\left(\frac{x}{a}\right)^{2}+\left(\frac{\xi}{\mathrm{b}}\right)^{2}+\left(\frac{z}{\mathrm{c}}\right)^{2}+d^{2}}
$$

$$
\begin{aligned}
a_{m} & =\frac{Q}{2 \pi k} \times a ; b_{m}=\frac{Q}{2 \pi k} \times b ; c_{m}=\frac{Q}{2 \pi k} \times c ; d_{m} \\
& =\frac{d}{\left(\frac{Q}{2 \pi k}\right)}
\end{aligned}
$$

$T=T_{0}$

$$
+\frac{1}{\sqrt{\left(\frac{x}{a_{m}}\right)^{2}+\left(\frac{\xi}{b_{m}}\right)^{2}+\left(\frac{z}{c_{m}}\right)^{2}+d_{m}^{2}}} e^{\left(-\frac{\rho c^{2 k}}{2 k}(R+\xi)\right)}
$$

Fig. 3 Comparison between the measurement and calculations using the Rosenthal equation according to temperature measurements taken at points 1 and 3

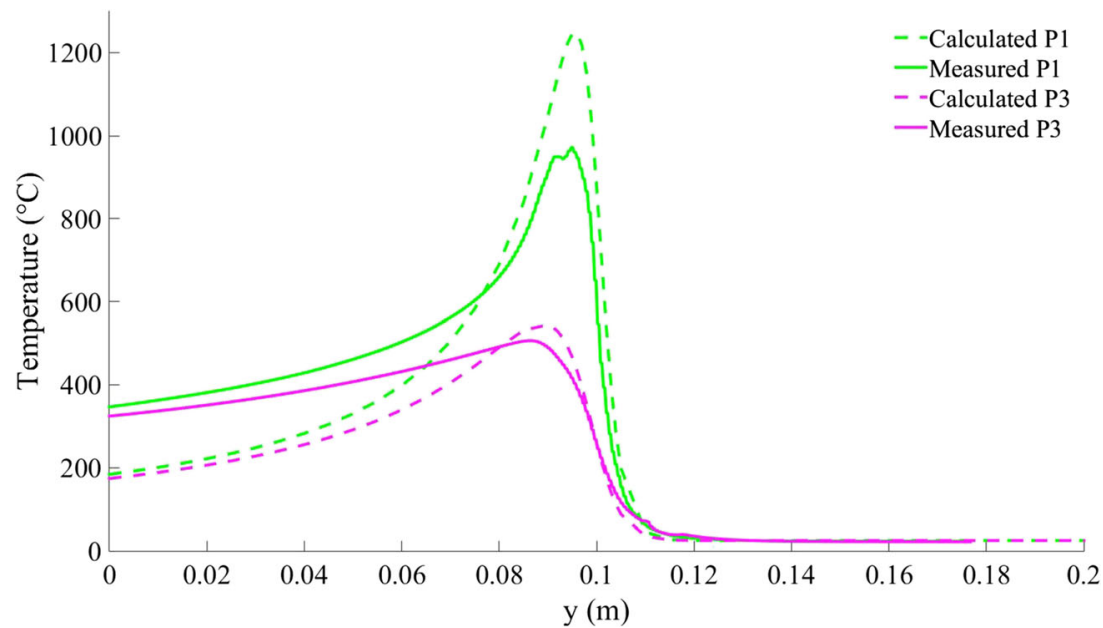




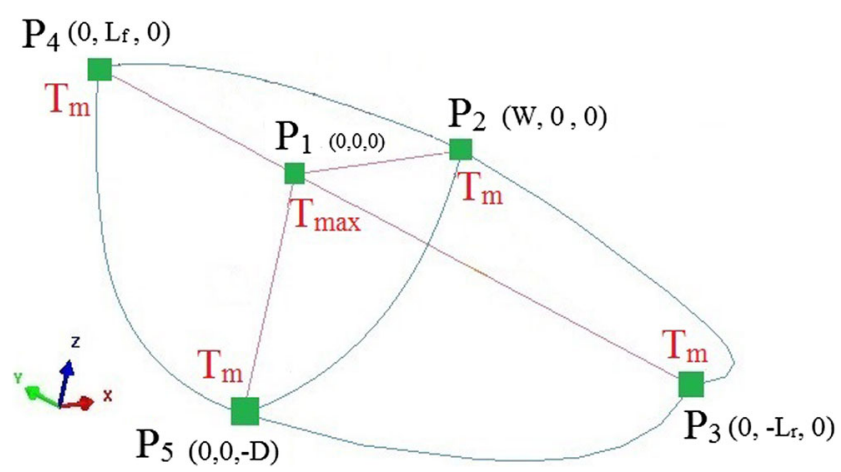

Fig. 4 Schematic of the assumed spatial volume of the weld pool

Therefore, the adaptive function is described as follows:

$T=T_{0}+\frac{1}{R_{p}} e^{\left(-\frac{\rho c v}{2 \mathrm{k}}(R+\xi)\right)}$

$R_{p}=\sqrt{\left(\frac{x}{a_{m}}\right)^{2}+\left(\frac{\xi}{b_{m}}\right)^{2}+\left(\frac{z}{c_{m}}\right)^{2}+d_{m}{ }^{2}}$

The term $\frac{\rho c}{2 \mathrm{k}}$ is a function of the heat diffusivity, which is a temperature-dependent material property in solid state, while the heat diffusivity in the weld pool strongly depends on the mass transfer. Since it is not possible to consider the temperature dependency of the physical properties and the mass transfer with an analytical equation, the term $\frac{\rho c}{2 \mathrm{k}} v$ is substituted by a constant value $B$, which is considered to be a parameter of the adaptive function.

$B=\frac{\rho c}{2 k} v$

Therefore, the adaptive function is defined as follows:
Table 6 Calculated parameters of the adaptive function obtained by solving the set of equations (Eq. 15-19)

\begin{tabular}{lllll}
\hline$a_{m}$ & $b_{m}$ & $c_{m}$ & $d_{m}$ & $B$ \\
\hline 10.6567 & 11.5913 & 3.6575 & $4.05 \times 10^{-4}$ & 52 \\
\hline
\end{tabular}

The parameter $d_{m}$ removes the singularity in the origin of the moving heat source (Eq. 15), and it is the main factor which determines the maximum temperature at the origin (center of the heat source). By considering the weld pool dimensions and an estimated maximum temperature $T_{\max }$ from the experiment, the optimum values of the parameters of Eq. 14 are determined so that the calculated fusion line coincides with the measurement. In accordance with Fig. 4, representing the weld pool, the temperature of P1 to P5 are known. Therefore, a set of five equations with five unknown parameters can be constructed and solved.

$$
\begin{aligned}
& T_{\max }=T(0,0,0)=T_{0}+\frac{1}{d_{m}} \\
& T_{\mathrm{m}}=T(W, 0,0)=T_{0}+\frac{1}{\sqrt{\left(\frac{W}{a_{m}}\right)^{2}+d_{m}^{2}}} e^{(-B W)} \\
& T_{\mathrm{m}}=T\left(0, L_{f}, 0\right)=T_{0}+\frac{1}{\sqrt{\left(\frac{L_{f}}{b_{m}}\right)^{2}+d_{m}^{2}}} e^{\left(-2 B L_{f}\right)}
\end{aligned}
$$

$$
\mathrm{Tm}=\mathrm{T}\left(0,-\mathrm{L}_{\mathrm{r}}, 0\right)=\mathrm{T}_{0}+\frac{1}{\sqrt{\left(\frac{\mathrm{L}_{\mathrm{r}}}{\mathrm{b}_{\mathrm{m}}}\right)^{2}+\mathrm{d}_{\mathrm{m}} 2}}
$$

Fig. 5 Temperature distribution on the upper surface of $316 \mathrm{~L}$ plate calculated by Eq. 14 and measured values

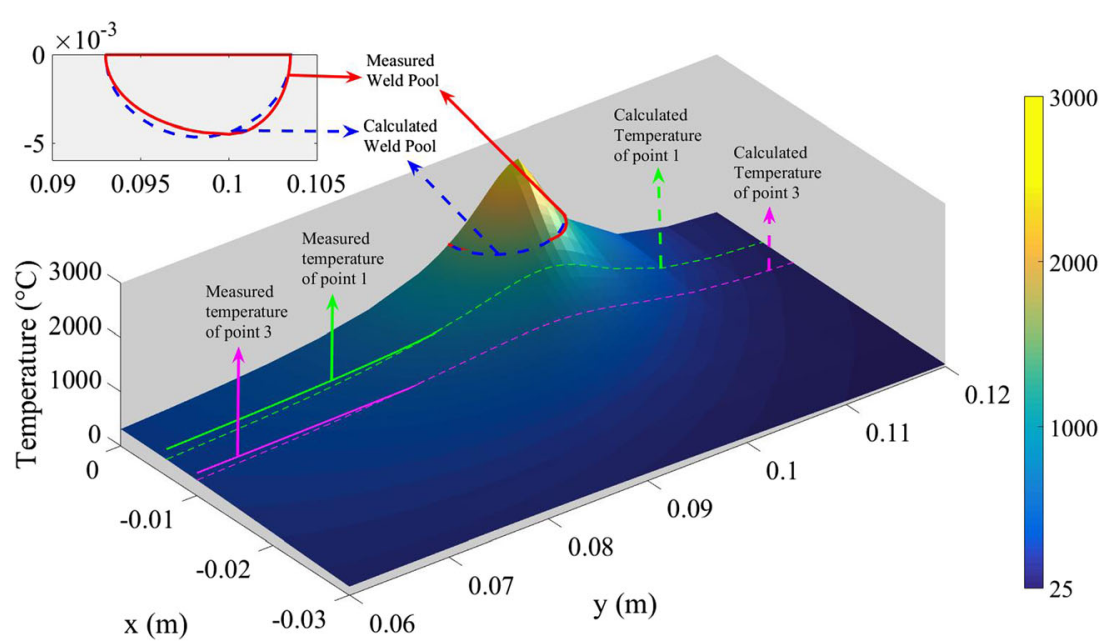


Fig. 6 Comparisons between the measurement and calculations using Eq. 14

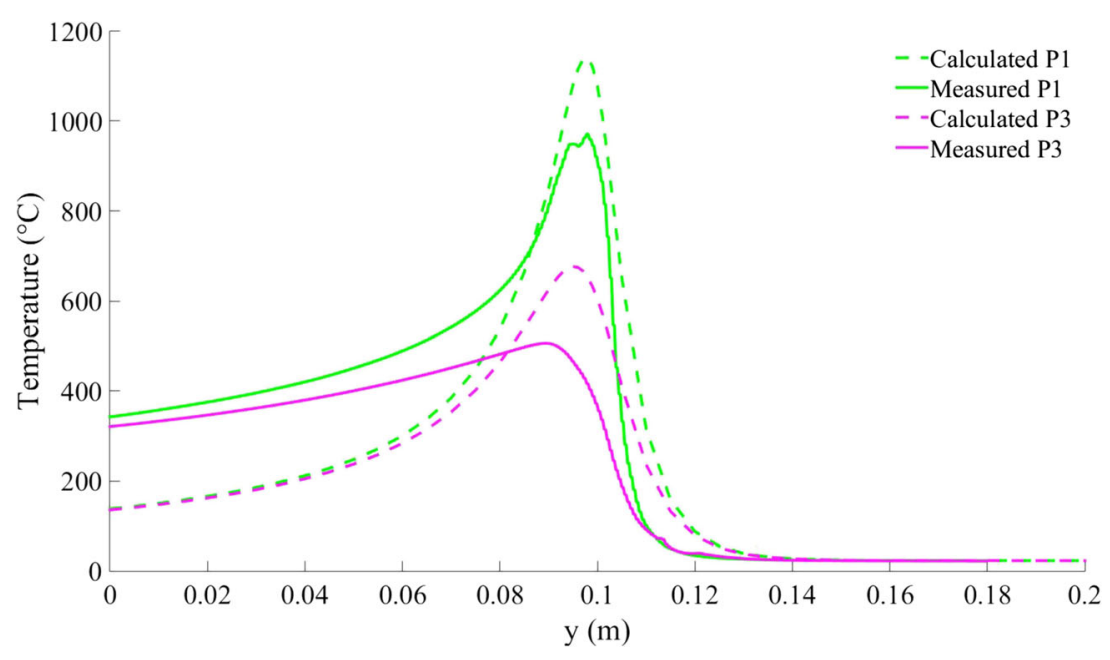

$\mathrm{T}_{\mathrm{m}}=\mathrm{T}(0,0,-\mathrm{D})=\mathrm{T}_{0}+\frac{1}{\sqrt{\left(\frac{\mathrm{D}}{\mathrm{c}_{\mathrm{m}}}\right)^{2}+\mathrm{d}_{\mathrm{m}}^{2}}} e^{(-\mathrm{BD})}$

The set of equations (Eq. 15-19) were solved in accordance with the weld pool dimensions given in Table 4, and considering an assumed maximum weld pool temperature of $2500{ }^{\circ} \mathrm{C}$. The calculated parameters of the adaptive function (Eq. 14) are summarized in Table 6.

Figure 5 shows the temperature distribution on the upper surface of the plate, which was calculated with the adaptive function and the parameters given in Table 6. As shown in Fig. 5, the singularity at the origin is removed, and the calculated fusion line coincides with the measurement.

Table 7 Estimated parameters of the modification function

\begin{tabular}{lllll}
\hline$M$ & $N_{x}$ & $N_{y f}$ & $N_{y r}$ & $N_{z}$ \\
\hline 0.45 & 0.45 & 0.45 & -0.24 & -0.44 \\
\hline
\end{tabular}

However, the calculated temperature in the rest of the plate (Fig. 6) still differs from the measurements taken.

\subsubsection{Modification function for matching the heat-affected zone}

The determined parameters $a_{m}, b_{m}$, and $c_{m}$ cause the adaptive function to match the real fusion line. But, as shown in Fig. 6, the distribution of temperature in the heat-affected zone still differs from measured ones. In order to adjust the adaptive function's result so that the calculated temperature match those in reality everywhere in addition to the fusion line, parameters $a_{m}, b_{m}$, and $c_{m}$ have to be adjusted accordingly.

Therefore, a modification function $f$ is defined based on a dimensionless parameter $\omega$. The dimensionless parameter $\omega$ changes the scale from a length unit $(\mathrm{m})$ to the scale of the weld pool dimensions, and it is expressed by the ratio of the coordinate of the point of interest to the dimensions of the weld pool in the same direction as defined in Eq. 20.
Fig. 7 Temperature distribution on the upper surface of $316 \mathrm{~L}$ plate calculated by Eq. 23

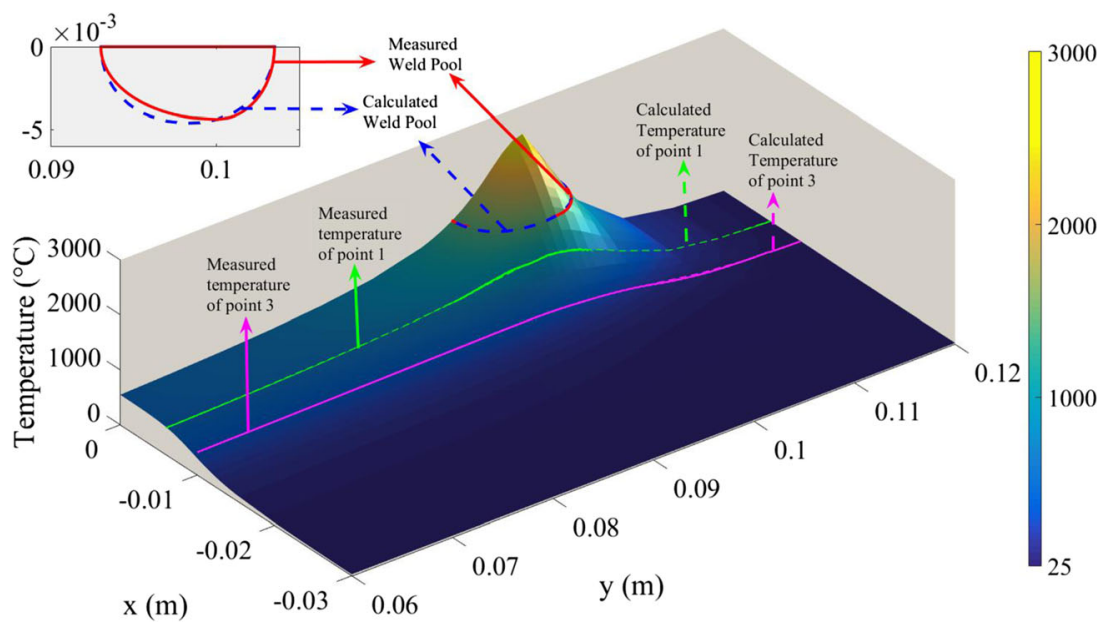

$\mathrm{x}(\mathrm{m})$ 
Fig. 8 Comparison between the measurement and calculations using Eq. 23
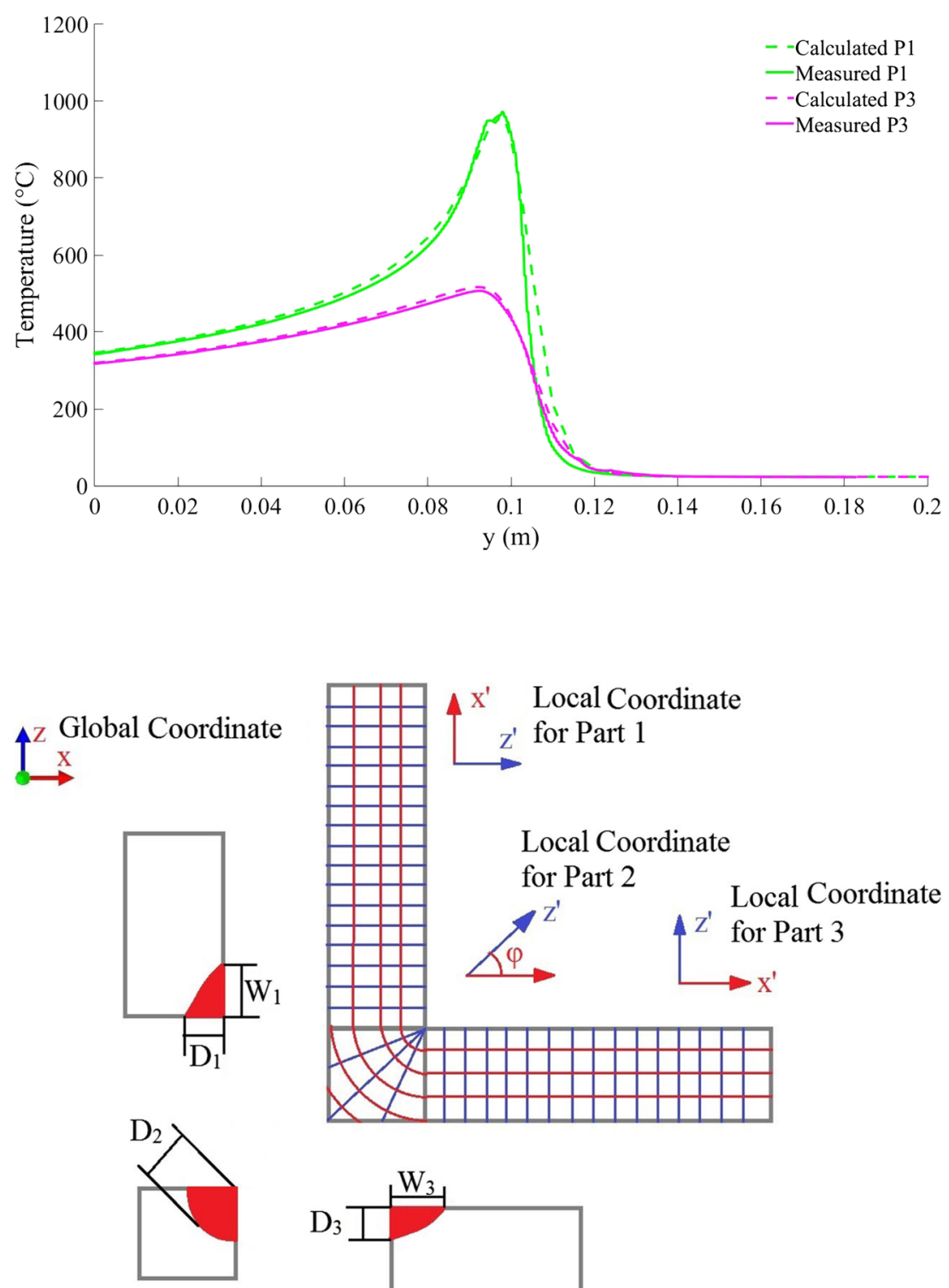
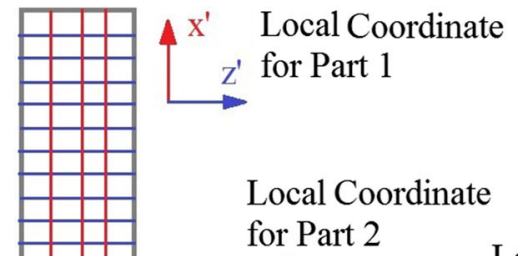
for Part 2

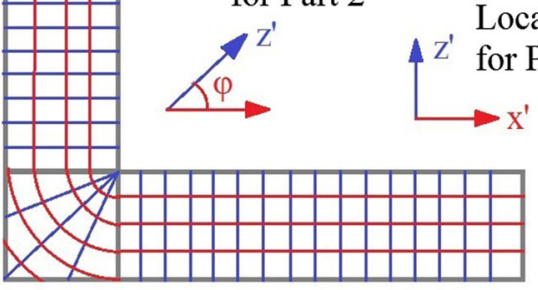

Local Coordinate

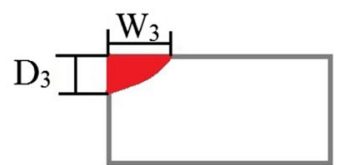

Fig. 9 Local and global coordinate systems for a fillet weld
$\omega_{x}=\frac{x}{W} ; \omega_{\xi f}=\frac{\xi}{L_{f}} ; \omega_{\xi r}=\frac{\xi}{L_{r}} ; \omega_{z}=\frac{z}{D}$

In order to avoid changing the melting isotherm, the modification function $f(\omega)$ should be 1 everywhere along the fusion line, which is defined by $\omega= \pm 1$.

$f( \pm 1)=1$

The modification function is proposed as follows:

$f(\omega)=\left(M \omega^{2}-M \sqrt{\omega^{2}}+1\right)^{N}$

Regardless of the amount of the $M$ and $N$, the result of the modification function is always 1 for inputs of \pm 1 . The modification function is used for all axes: the $x$-axis, $y$-axis toward the back of the welding torch $(\xi<0), y$ axis toward the front of the welding torch $(\xi>0)$, and the $z$-axis. The final form of the adaptive function is described in Eq. 23-25, and the estimated parameters of the modification function are presented in Table 7. The parameters of the modification function are estimated based on decreasing the overall error of the computation.

$T=T_{0}+\frac{1}{R_{p}} e^{(-B(R+y))}$

Table 8 Parameters of the welding processes and size of weld plates

\begin{tabular}{|c|c|c|c|c|c|c|}
\hline \multirow{2}{*}{$\begin{array}{l}\text { Test } \\
\text { no. }\end{array}$} & \multicolumn{3}{|c|}{ Plate size (mm) } & \multirow{2}{*}{$\begin{array}{l}\text { Welding } \\
\text { current } \\
\text { (A) }\end{array}$} & \multirow{2}{*}{$\begin{array}{l}\text { Voltage } \\
\text { (V) }\end{array}$} & \multirow{2}{*}{$\begin{array}{l}\text { Speed } \\
(\mathrm{mm} / \\
\mathrm{s})\end{array}$} \\
\hline & Width & Length & Thickness & & & \\
\hline 1 & 100 & 200 & 10 & 150 & 14 & 1.5 \\
\hline 2 & & & & 175 & 15 & \\
\hline
\end{tabular}


Fig. 10 Welding setup and positions of the thermocouples

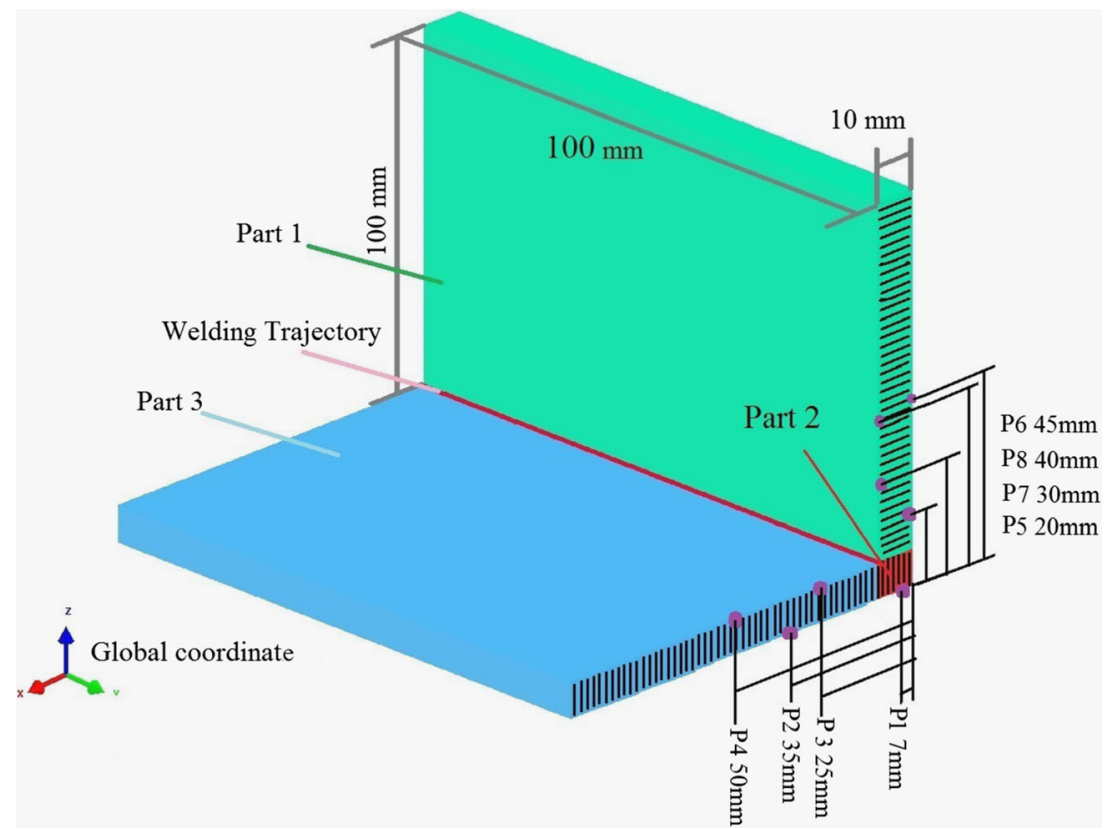

$R_{p}=\sqrt{\left(f\left(\frac{x}{W}\right) \times \frac{x}{a_{m}}\right)^{2}+\left(f\left(\frac{\xi}{L_{f}}\right) \times \frac{\xi}{b_{m}}\right)^{2}+\left(f\left(\frac{z}{D}\right) \times \frac{z}{c_{m}}\right)^{2}+d_{m}{ }^{2}} \quad ; \xi \geq 0$

$R_{p}=\sqrt{\left(f\left(\frac{x}{W}\right) \times \frac{x}{a_{m}}\right)^{2}+\left(f\left(\frac{\xi}{L_{r}}\right) \times \frac{\xi}{b_{m}}\right)^{2}+\left(f\left(\frac{z}{D}\right) \times \frac{z}{c_{m}}\right)^{2}+d_{m}{ }^{2}} \quad ; \xi<0$

The temperature distribution was calculated using Eq. 23 with the estimated parameters of the modification function given in Table 7. Figure 7 and Figure 8 show that the measured temperature and the calculated temperature match one another along with the matching of the calculated and measured fusion line.

\section{Adaptive function for a fillet weld}

In order to apply the adaptive function to fillet arc welding, the welding geometry, and the weld pool are divided into three parts, including the weld plates and the conjunction of the plates as shown in Fig. 9.

Table 9 Weld pool size ( $\mathrm{mm})$

\begin{tabular}{llllll}
\hline Test no. & $W_{1}$ and $W_{3}$ & $L_{f}$ & $L_{r}$ & $\begin{array}{l}D_{1} \text { and } \\
D_{2}\end{array}$ & $D_{3}$ \\
\hline 1 & 4.5 & 3.5 & 7 & 1.7 & 1.9 \\
2 & 5 & 4 & 9.8 & 1.9 & 2.1 \\
\hline
\end{tabular}

The adaptive function is applied in each part separately, and accordingly, a local coordinate system is defined for each part. Parts 1 and 3 are assumed to be a plate subjected to a heat source which produces a weld pool with distinct dimensions just similar to a bead on plate welding. According to this assumption, the local coordinate system is defined so that the $z$-axis is parallel to the weld penetration direction (depth direction of the weld plate), the $x$-axis is parallel to the fillet weld legs (width direction of the weld plate), and the $y$-axis is parallel to the welding trajectory (Fig. 9). The parameters of the adaptive function are determined according to the weld dimensions of parts 1 and 3 .

In the case of part 2, it is assumed that the heat flows radially within part 2 and, thus, a polar coordinate system is defined for this part. The adaptive function for this part is redesigned so that the consistency of the calculated temperature distribution can be preserved. Accordingly, a new term as a function of the polar angle $(\varphi)$ is defined so that the result calculated by the adaptive function for each part will be equal in the planes in which the parts are connected.

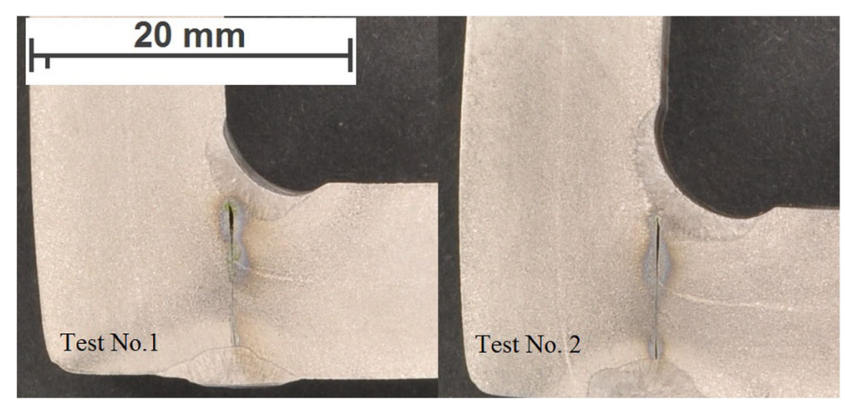

Fig. 11 Weld cross-sections 
Table 10 Estimated parameters of the modification function

\begin{tabular}{cccccccccccc}
\hline Test no. & $B$ & $M$ & $N_{x}$ & $N_{y f}$ & $N_{y r}$ & $N_{z}$ & $a_{m}$ & $b_{m}$ & $c_{m}$ & $d_{m}$ & $\delta$ \\
\hline 1 & 52 & 0.45 & 0.45 & 0.45 & -0.24 & -0.44 & 10.65 & 11.59 & 2.79 & $4.05 \times 10^{-4}$ & $9.38 \times 10^{-8}$ \\
2 & 52 & 0.45 & 0.45 & 0.45 & -0.24 & -0.44 & 13.17 & 16.38 & 3.25 & $4.05 \times 10^{-4}$ & $9.38 \times 10^{-8}$ \\
\hline
\end{tabular}

According to Eqs. 26 and 27, the term containing $(\varphi)$ is zero in the connection planes and, regardless the local coordinate systems, the calculated temperature is always the same. The parameter $\delta$ of the new term is determined according to the weld penetration $D_{2}$ in part 2 (Eq. 28).

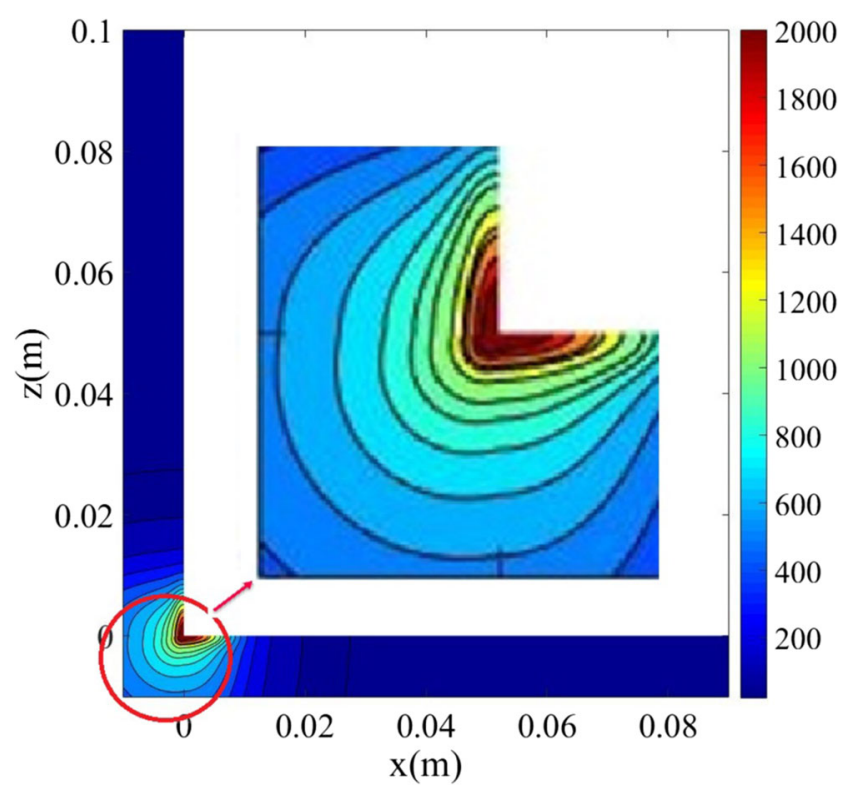

Fig. 12 Temperature distribution in the weld cross-section $\xi=0$
$R_{p}=\sqrt{\left(f\left(\frac{\xi}{L_{f}}\right) \times \frac{\xi}{b_{m}}\right)^{2}+\left(f\left(\frac{z}{D_{2}}\right) \times \frac{z}{c_{m}}\right)^{2}-\delta\left(\frac{z}{z+d_{m}}\right)^{2} \cos 2 \varphi+d_{m}{ }^{2}} ; \xi \geq 0$

$R_{p}=\sqrt{\left(f\left(\frac{\xi}{L_{r}}\right) \times \frac{\xi}{b_{m}}\right)^{2}+\left(f\left(\frac{z}{D_{2}}\right) \times \frac{z}{c_{m}}\right)^{2}-\delta\left(\frac{z}{z+d_{m}}\right)^{2} \cos 2 \varphi+d_{m}{ }^{2}} ; \xi \leq 0$

$\delta=\frac{\left(\frac{D_{2}}{c_{m}}\right)^{2}+d_{m}{ }^{2}-\left(\frac{e^{\left(-B D_{2}\right)}}{T_{m}}\right)^{2}}{\left(\frac{D_{2}}{D_{2}+d_{m}}\right)^{2}}$

\section{Example}

\subsection{Model description}

Two stainless steel 316L plates of equal size were welded using GTAW without a filler metal. Two different welding parameter sets were applied, which are presented in Table 8.

In order to verify the adaptive function method, eight thermocouples were installed on the welding plates as shown in Fig. 10. The weld pool dimensions for each part of the fillet weld were measured and are given in Table 9. Figure 11 shows the cross-section of both fillet welds.
Fig. 13 Calculated and measured time-temperature curves at point no. 1 for tests nos. 1 and 2

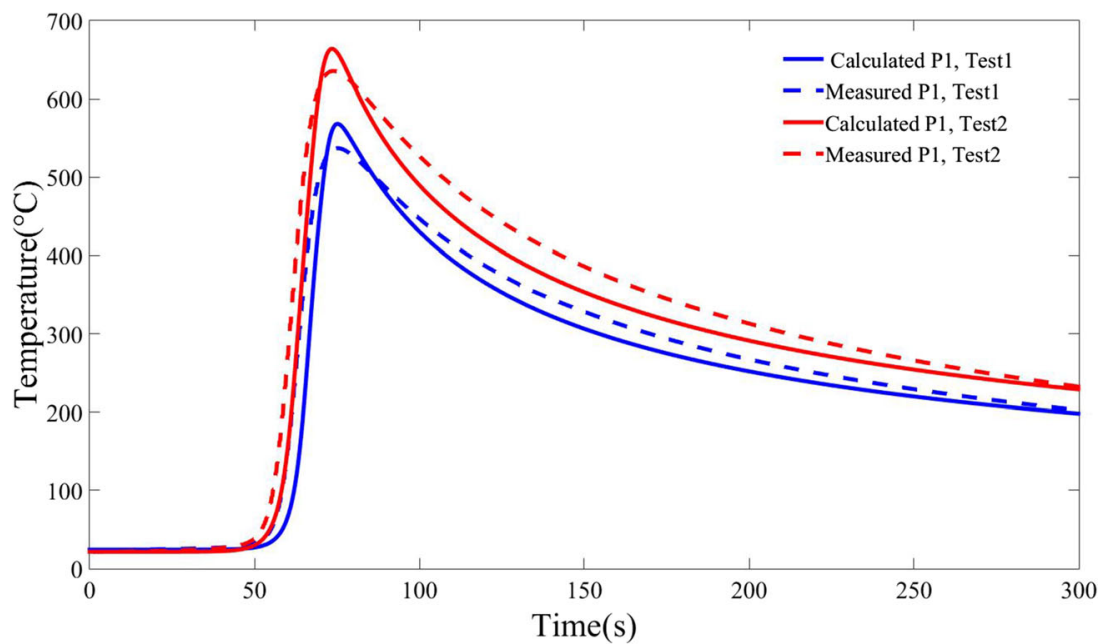


Fig. 14 Calculated and measured time-temperature curves at point no. 3 for tests nos. 1 and 2

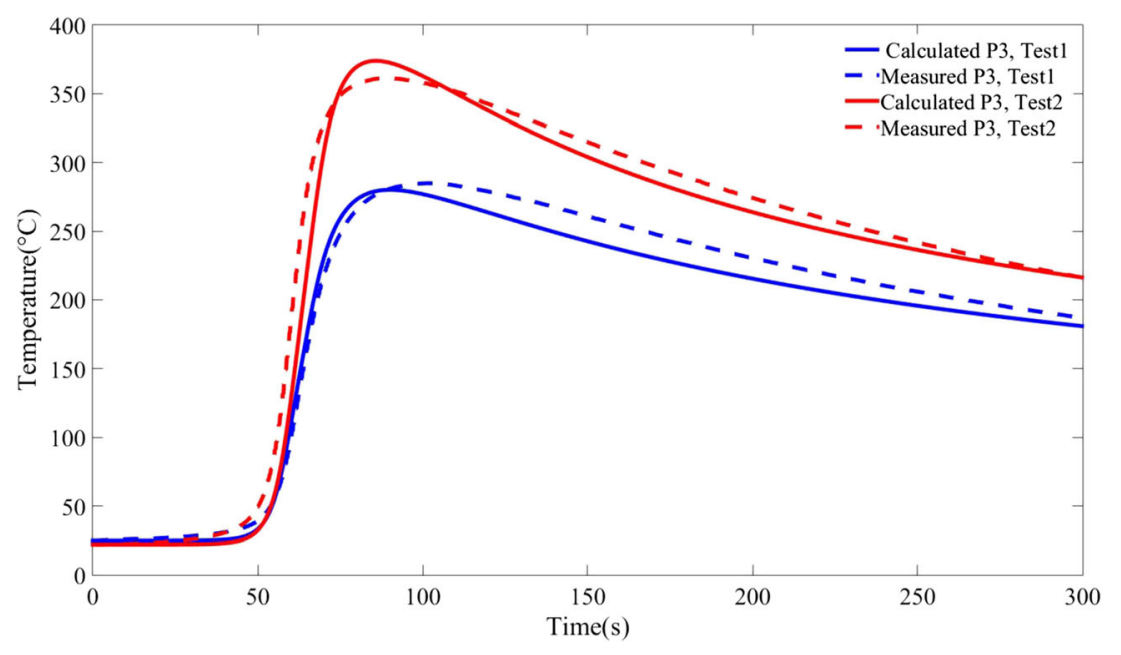

Fig. 15 Calculated and measured time-temperature curves at point no. 7 for tests nos. 1 and 2

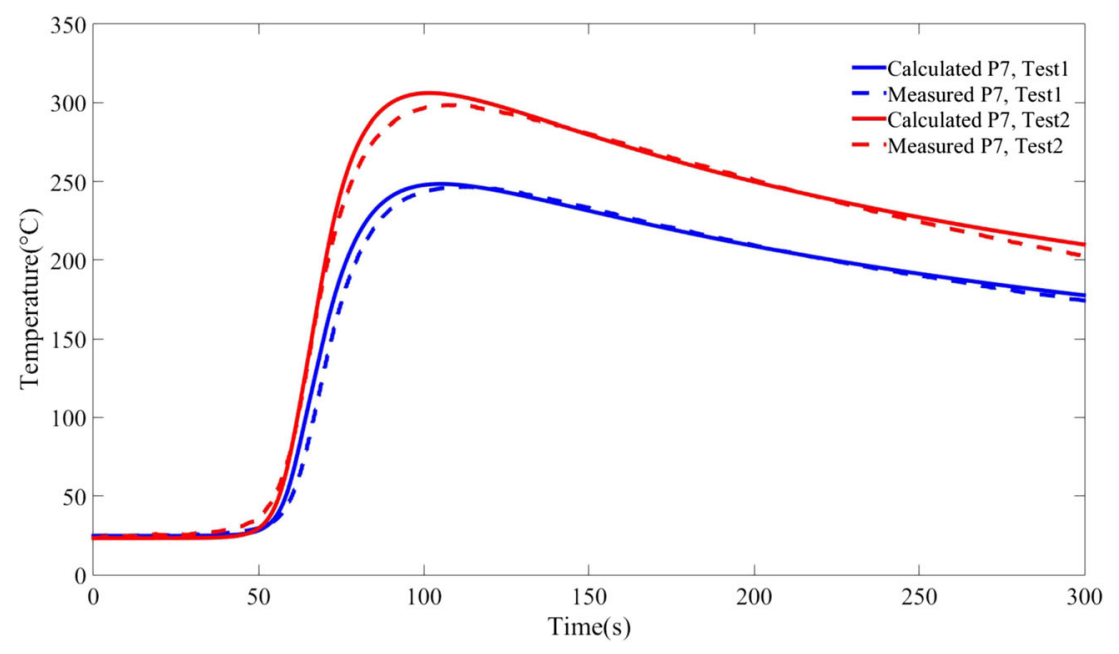

\subsection{Results and discussion}

Using experimental data, the parameters of the adaptive function were calculated for both experiments and are presented in Table 10.

The estimated parameters of the modification function including $M, N_{x}, N_{y f}, N_{y r}$, and $N_{z}$ are the same for both weldings as well as for the bead on plate welding presented in Table 7. The parameters of the adaptive function increase by increasing the weld pool dimensions which is, in turn, because of the higher heat input.

Figure 12 shows the temperature distribution in the weld cross-section which indicates the consistency of the isotherms. Figures 13, 14, and 15 show the measured and calculated temperature for points no. 1 , no. 3 , and no. 7 . The adaptive function results agree well with the measurement.

\section{Conclusion}

The solution to the heat flow problem in welding proposed in this paper is a general method that can be used to solve the partial differential equation with high accuracy and low computation cost. The parameters of the adaptive function are directly determined by temperature measurement and no information about material properties and heat source parameters are required.

In addition, the proposed adaptive function enables researchers to conduct further investigations on the effects of welding circumstances (welding heat input, welding traveling speed, and geometry of the weld piece) on the temperature distribution by directly using experimental data.

Acknowledgements Open access funding provided by Graz University of Technology.

Open Access This article is distributed under the terms of the Creative Commons Attribution 4.0 International License (http:// creativecommons.org/licenses/by/4.0/), which permits unrestricted use, distribution, and reproduction in any medium, provided you give appropriate credit to the original author(s) and the source, provide a link to the Creative Commons license, and indicate if changes were made. 


\section{References}

1. Nasiri MB, Enzinger N (2018) Powerful analytical solution to heat flow problem in welding. Int J Therm Sci 134:1-13. https://doi.org/ 10.1016/j.ijthermalsci.2018.08.003

2. David Leroy Olson, Thomas A. Siewert, Stephen Liu GRE (1993) ASM handbook: welding, brazing, and soldering. ASM International

3. Rosenthal D (1946) The theory of moving source of heat and its application to metal transfer. ASME Trans 43:849-866

4. Nippes EF, Savage WF, Allis RJ (1957) Studies of the weld heat affected zone of T-1 steel. Weld J 36:531-540

5. Christensen N, Davies V, Gjermundsen K (1965) Distribution of temperatures in arc welding. Br Weld J 12:54-75

6. Eagar TW, Tsai NS (1983) Temperature fields produced by traveling distributed heat sources. Weld J 62:346-355

7. Komanduri R, Hou ZB (2000) Thermal analysis of the arc welding process: part I. General solutions. Metall Mater Trans B Process Metall Mater Process Sci 31:1353-1370. https://doi.org/10.1007/ s11663-000-0022-2

8. N.T.Nguyen, A.Ohta, K.Matsuoka, et al (1999) Analytical solutions for transient temperature of semi-infinite body subjected to 3-D moving heat sources. Weld Res Suppl I:265-274

9. Lindgren L-E (2001) Finite element modeling and simulation of welding. Part 2: improved material modeling. J Therm Stress 24: 195-231. https://doi.org/10.1080/014957301300006380
10. Goldak JA, Akhlaghi M (2005) Computational welding mechanics. Comput Weld Mech. doi: https://doi.org/10.1007/b101137

11. Azar AS, As SK, Akselsen OM (2012) Determination of welding heat source parameters from actual bead shape. Comput Mater Sci 54:176-182. https://doi.org/10.1016/j.commatsci.2011.10.025

12. Jeong SK, Cho HS (1997) An analytical solution to predict the transient temperature distribution in fillet arc welds. Weld JournalIncluding Weld Res Suppl 76:223s

13. Nasiri MB, Behzadinejad M, Latifi H, Martikainen J (2014) Investigation on the influence of various welding parameters on the arc thermal efficiency of the GTAW process by calorimetric method. J Mech Sci Technol 28:3255-3261. https://doi.org/10. 1007/s12206-014-0736-8

14. Dong P (2001) Residual stress analyses of a multi-pass girth weld: 3-D special shell versus axisymmetric models. J Press Vessel Technol 123:207. https://doi.org/10.1115/1.1359527

15. Jiang W, Zhang Y, Woo W (2012) Using heat sink technology to decrease residual stress in $316 \mathrm{~L}$ stainless steel welding joint: finite element simulation. Int J Press Vessel Pip 92:56-62. https://doi.org/ 10.1016/j.ijpvp.2012.01.002

16. Ficquet X, Smith DJ, Truman CE, Kingston EJ, Dennis RJ (2009) Measurement and prediction of residual stress in a bead-on-plate weld benchmark specimen. Int J Press Vessel Pip 86:20-30. https:// doi.org/10.1016/j.ijpvp.2008.11.008 